\title{
COMPOSIÇÃO CENTESIMAL E COLESTEROL DA CARNE DE JACARÉ-DÓ-PANTANAL (Caiman yacare Daudin 1802) ORIUNDO DE ZOOCRIADOURO E HABITAT NATURAL ${ }^{1}$
}

\author{
Proximate composition and cholesterol of the alligator-swampland meat \\ (Caiman yacare Daudin 1802) originating from captivity and wild life
}

\author{
João Vicente Neto ${ }^{2}$, Maria Cristina Bressan ${ }^{3}$, Peter Bitencourt Faria ${ }^{4}$, \\ Josye Oliveira e Vieira ${ }^{5}$, Merce Teodora Aguil Santana ${ }^{6}$, Marcos Kloster ${ }^{7}$
}

\begin{abstract}
RESUMO
Foram utilizados 12 animais, sendo 06 (peso médio de 5,93 kg) oriundos de zoocriadouro (Z) autorizado pelo Instituto Brasileiro do Meio Ambiente e dos Recursos Naturais Renováveis (IBAMA), Estado do Mato Grosso, Brasil, e 06 (peso médio de 6,78 kg) oriundos do habitat natural $(\mathrm{H})$, provenientes do município de Cáceres - MT. As amostras foram coletadas dos músculos ílio-ischiocaudalis e occipito-cervicalis medialis, cauda e dorso, respectivamente. Nesses músculos foram determinados: umidade, extrato etéreo, proteína e cinzas. A extração de lipídeos foi conduzida com uso de clorofórmio/metanol (2:1). O colesterol foi determinado por colorimetria em espectrofotômetro. O corte da cauda dos jacarés $\mathrm{Z}$ apresentou médias de 74,50;24,20;0,83; 0,91\% e o corte dorso 76,20; 23,68; 0,49 e 0,99\% para umidade, proteína, extrato etéreo e cinzas, respectivamente. Nos animais H, as médias foram 72,29; 21,$83 ; 5,43$ e $1,09 \%$ na cauda e 76,70; 21,$93 ; 0,54$ e $1,25 \%$ no dorso (umidade, proteína, extrato etéreo e cinzas, respectivamente). As médias de colesterol nos animais $\mathrm{Z}$ foram de 48,82 e de $53,73 \mathrm{mg} / 100 \mathrm{~g}$ na cauda e dorso, respectivamente. Nos animais $\mathrm{H}$, as médias foram de 37,05 $\mathrm{mg} / 100 \mathrm{~g}$ na cauda e 40,61 mg/100 g no dorso. Assim, os jacarés de $\mathrm{Z}$ apresentaram carne mais magra, do que os jacarés $\mathrm{H}$. E quando comparados os cortes, a cauda apresentou mais proteína e extrato etéreo, enquanto o dorso apresentou mais umidade, cinzas e colesterol.
\end{abstract}

Termos para indexação: Animal silvestre, carne, composição centesimal.

\begin{abstract}
They were used 12 animals, 06 (with average weight of $5.93 \mathrm{~kg}$ ) originating from captivity, authorized by Instituto Brasileiro do Meio Ambiente e dos Recursos Naturais Renováveis (IBAMA), Mato Grosso state, Brazil, and 06 (with average weight of 6.78 $\mathrm{kg}$ ) originating from natural habitat, every animals coming from municipal district of Cáceres, Mato Grosso state, Brazil. The samples were collected of the muscles ílio-ischio-caudalis and occipito-cervicalis medialis, tail and back, respectively. In those muscles they were determined: moisture, ethereal extract, protein and ashes. The lipids extraction was driven with chloroform/methanol (2:1). The cholesterol was determined by colorimeter in spectrophotometer. The cut tail of the alligators originating from captivity presented averages of $74.50 ; 24.20 ; 0.83 ; 0.91 \%$ and the cut back $76.20 ; 23.68 ; 0.49$ and $0.99 \%$ for moisture, protein, ethereal extract and ashes, respectively. In the animals originating from natural habitat, the averages were $72.29 ; 21.83 ; 5.43$ and $1.09 \%$ in the tail and 76.70 ; 21.93; 0.54 and $1.25 \%$ in the back (moisture, protein, ethereal extract and ashes, respectively). The cholesterol averages in the animals originating from captivity were of 48.82 and of $53.73 \mathrm{mg} / 100 \mathrm{~g}^{-1}$ in the tail and back, respectively. In the animals originating from natural habitat the averages were of $37.05 \mathrm{mg} / 100 \mathrm{~g}^{-1}$ in the tail and $40.61 \mathrm{mg} / 100 \mathrm{~g}$ in the back. Thus, the alligators originating from captivity presented thinner meat, than the alligators originating from natural habitat. When comparing the cuts, the tail presented higher protein and ethereal extract, while the neck presented higher moisture, ashes and cholesterol.
\end{abstract}

Index terms: Wild animal, meat, proximate composition.

(Recebido para publicação em 19 de abril de 2005 e aprovado em 7 de outubro de 2005)

\section{INTRODUÇÃO}

A carne é considerada um alimento nobre para o homem, pois contribui, na dieta, com proteínas de alto valor biológico, ácidos graxos essenciais e vitaminas do complexo B (PARDI et al., 1993). Por outro lado, normalmente as carnes de animais domésticos apresentam elevados teores de ácidos graxos saturados, considerados responsáveis pela elevação da concentração sérica de colesterol. Em contrapartida, as carnes de animais silvestres apresentam reduzidos teores de lipídeos totais e apresentam altas proporções de ácidos graxos poliinsaturados (CRAWFORD et al., 1976; DREW, 1985; NAUGHTON et al., 1986; SINCLAIR \& O’DEA, 1990).

\footnotetext{
${ }^{1}$ Parte da Dissertação de Mestrado do primeiro autor apresentada ao Departamento de Ciência dos Alimentos da Universidade Federal de Lavras/UFLA.

2 Professor, MSc em Ciência dos Alimentos, da Escola Agrotécnica Federal de Cáceres - Cáceres, MT. joviceneto@yahoo.com.br

${ }^{3}$ Professora do Departamento de Ciência dos Alimentos da Universidade Federal de Lavras/UFLA - CX. P. 3037 - $37200-000$ - Lavras, MG. bressan@ufla.br

${ }^{4}$ Professor do Centro Federal de Educação Tecnológica de Cuiabá, MT.

${ }^{5}$ Veterinária da Empresa Rações Total - Três Corações, MG.

${ }^{6}$ Extensionista do CEFET - Rio Verde, GO.

${ }^{7}$ Zootecnista da Cooperativa de Criadores de Jacaré-do-pantanal - Cáceres, MT.
} 
A composição centesimal corresponde à proporção de grupos homogêneos de substâncias, os quais dizem respeito àqueles compostos que se encontram em praticamente todos os alimentos, em $100 \mathrm{~g}$, exprimindo parcialmente o seu valor nutritivo (VILAS BOAS, 1999). Em relação à composição centesimal, a carne magra apresenta em torno de $75 \%$ de água, 21 a $22 \%$ de proteína, 1 a $2 \%$ de gordura, $1 \%$ de minerais e menos de $1 \%$ de carboidratos.

A composição química da carne sofre variações em função da fase de crescimento do músculo; da idade; da espécie animal; da nutrição e da condição sexual (FORREST et al., 1979). O efeito geral da alimentação e do nível nutricional sobre o crescimento dos animais produtores de carne se reflete na composição dos diversos músculos. O percentual de água nos músculos diminui com o aumento da idade, por causa do aumento da concentração de proteínas e gorduras com o crescimento. $\mathrm{O}$ componente mais variável dos músculos e do organismo animal é o lipídeo total, pois o seu aumento não depende, necessariamente, do crescimento muscular, e sim de sua dieta (LAWRIE, 1967; FORREST et al., 1979; PRÄNDL et al., 1994; PRICE \& SCHWEIGGERT, 1976).

Em seu habitat natural, a dieta do jacaré-do-pantanal durante a estação seca é constituída por insetos e peixes (SANTOS, 1997). Em cativeiro ou zoocriadouros, o jacaré é alimentado com uma ração, em que a proteína animal é oriunda de uma mistura de vísceras bovinas moídas (pulmão e baço), farinha de sangue e farinha de carnes (ALEIXO, 2000; MACIEL, 2001).

Os primeiros estudos efetuados com carne de jacaré para consumo humano foram realizados por Moody et al. (1980), na Lousiana (Estados Unidos), com jacaré (Alligator mississippiensis, Daudin 1801), em que foram desenvolvidas técnicas para o abate, processamento e estudos da composição da carne em diferentes cortes do animal. Nesse estudo, foram avaliados quatro cortes de animais selvagens e os autores reportaram médias de proteínas totais variando de 21,1 a $22,3 \%$; umidade, 73 a $76,8 \%$; extrato etéreo, 1 a $1,5 \%$; e cinzas, 1 a $1,5 \%$. Entretanto, os autores não citaram o peso dos animais estudados.

No Brasil, Romanelli (1995), estudando as propriedades tecnológicas da carne de jacaré-do-pantanal (Caiman yacare), com dois grupos de pesos diferentes, 2 a $4 \mathrm{~kg}$ e 16,50 a 20,90 kg, reportou médias para proteína de 18,40 a $18,43 \%$; umidade, 75,23 a 78,33\%; lipídeos totais, 2,25 a $5,32 \%$; e cinzas, 1,02 a $1,08 \%$, para as duas categorias de peso, respectivamente.
Objetivou-se com o presente trabalho determinar a composição centesimal e colesterol dos cortes cauda e dorso de jacarés-do-pantanal, oriundos de zoocriadouro e habitat natural.

\section{MATERIAL E MÉTODOS}

Foram utilizados 12 jacarés da espécie Caiman yacare, sendo 06 animais (Tratamento 1) oriundos do zoocriadouro (Z), localizado no município de Cáceres MT, devidamente registrado pelo IBAMA-MT sob n ${ }^{\circ} 1 /$ 51/92/0197-0, com peso médio de 5,93 kg; e 06 animais (Tratamento 2) oriundos do habitat natural $(\mathrm{H})$, capturados sob licença do IBAMA-MT no município de Cáceres - MT, com peso médio de 6,78 kg. Os animais foram abatidos em julho de 2004, em frigorífico específico para jacaré localizado no município de Cáceres - MT, seguindo os padrões higiênicos sanitários determinados pela legislação vigente.

As amostras utilizadas nas determinações de composição centesimal e colesterol foram coletadas às 24 horas post mortem da porção medial do músculo ílio-ischiocaudalis e do músculo occipito-cervicalis medialis (REESE, 2000), que correspondem aos cortes de cauda e dorso, respectivamente. As porções dos músculos foram envolvidas em filme pvc, recobertas em papel alumínio, e congeladas a $-21^{\circ} \mathrm{C}$ em túnel de congelamento de ar forçado, e estocadas em câmara fria a $-18{ }^{\circ} \mathrm{C}$ até o momento das análises. As análises foram efetuadas no laboratório de Ciência e Tecnologia de Carnes da Universidade Federal de Lavras - MG.

No momento das análises, as amostras foram descongeladas a $3,5 \pm 0,5{ }^{\circ} \mathrm{C}$. Para a determinação da composição centesimal, as amostras foram homogeneizadas em multiprocessador até a obtenção de uma massa homogênea. As análises de proteína bruta, extrato etéreo, umidade e cinzas foram realizadas segundo AOAC (1990). Na análise de colesterol, os lipídeos foram extraídos com clorofórmio/metanol (2:1) (FOLCH et al., 1957). O teor de colesterol foi determinado colorimetricamente (BOHAC et al., 1988, adaptado por BRAGAGNOLO \& RODRIGUEZ-AMAYA, 1995).

$\mathrm{O}$ experimento foi conduzido em um delineamento inteiramente casualizado, com os tratamentos em esquema fatorial $2 \times 2$, duas origens, dois cortes com seis (6) repetições. Os dados obtidos foram analisados no programa estatístico SISVAR versão 4.0 (FERREIRA, 2000), aplicando-se o teste F, com nível de significância de $5 \%$. 


\section{RESULTADOS E DISCUSSÃO}

As médias de umidade, extrato etéreo, proteína, cinzas e colesterol nos cortes cauda e dorso de jacarédo-pantanal, oriundo de zoocriadouro (Z) e habitat natural (H) estão apresentadas na Tabela 1.

Houve interação significativa $(\mathrm{P}<0,05)$ nas respostas de umidade e extrato etéreo para os fatores origens e cortes. Tanto para os animais $\mathrm{Z}$ como os animais do $\mathrm{H}$, o corte dorso apresentou maior valor de umidade $(76,45 \%)$ do que a cauda $(73,39 \%)$. Entretanto, observouse que na cauda houve diferença $(\mathrm{P}<0,05)$ entre origem, sendo que os animais $\mathrm{Z}$ apresentaram valor mais elevado (74,50\%) de umidade do que os animais $\mathrm{H}(72,29 \%)$. Essa diferença possivelmente se deve ao fato de os animais $\mathrm{Z}$ serem mais jovens, do que os animais $\mathrm{H}$. O teor percentual em água (umidade) diminui com o aumento da idade, decorrente do aumento da concentração de proteínas e gorduras no tecido muscular com a evolução das fases de crescimento (FORREST et al., 1979; PRÄNDL et al., 1994; SOUZA, 2001). O fato dos cortes apresentarem diferença $(\mathrm{P}<0,05)$ em umidade se explica pelo aumento da média de extrato etéreo $(3,13$ e $0,51 \%$, na cauda e no dorso, respectivamente).
Romanelli (1995) reporta valores de umidade para carne de jacaré-do-pantanal variando de 75,23\% e 78,33\% para animais de 16,50 a $20,90 \mathrm{~kg}$ e de 2,0 a $4,0 \mathrm{~kg}$, respectivamente. Moody et al. (1980) encontraram valores variando de 73 a $76,8 \%$ para umidade nos quatro cortes analisados em carne de jacaré americano selvagem. Para outro animal silvestre, a capivara, é descrito médias de umidade variando de 75,09 a 77,29\% (JARDIM, 2001; MIGUEL, 2002; SALDANHA, 2000).

Houve diferença $(\mathrm{P}<0,05)$ entre as origens para os valores de extrato etéreo. Os animais $\mathrm{H}$ apresentaram valor mais elevado $(2,98 \%)$ do que os animais $\mathrm{Z}(0,66 \%)$. Isso pode ser atribuído a maior necessidade de reserva lipídica requerida nos animais do habitat natural (do que naqueles de zoocriadouro), como fonte energética para estes músculos, nos períodos de maior escassez de alimentos. Esse aumento no valor de extrato etéreo dos animais $\mathrm{H}$ foi acompanhado pela redução nas médias de proteína e umidade. Entretanto, valor mais elevado de extrato etéreo foi encontrado na cauda ( $0,83 \%$ e 5,43\%, em animais $\mathrm{Z}$ e $\mathrm{H}$, respectivamente). A cauda apresenta músculos com atividade física mais intensa em razão da locomoção em ambientes aquáticos, necessitando, para tanto, de reservas de energia.

TABELA 1 - Médias de umidade, proteína, extrato etéreo, cinzas e colesterol na matéria natural da carne de jacaré-dopantanal. Lavras/MG, 2005.

\begin{tabular}{|c|c|c|c|c|}
\hline \multirow{6}{*}{ Umidade $(\%)$} & \multirow{2}{*}{ Origem } & \multicolumn{2}{|c|}{ Corte } & \multirow[b]{2}{*}{ Média } \\
\hline & & Cauda & Dorso & \\
\hline & Zoocriadouro & $74,50^{\mathrm{aB}}$ & $76,20^{\mathrm{aA}}$ & \multirow{4}{*}{$\begin{array}{l}75,35 \\
74,49\end{array}$} \\
\hline & Habitat Natural & $72,29^{\mathrm{bB}}$ & $76,70^{\mathrm{aA}}$ & \\
\hline & Média & 73,39 & 76,45 & \\
\hline & CV $(\%)$ & & & \\
\hline \multirow{4}{*}{ Proteína (\%) } & Zoocriadouro & 24,20 & 23,67 & \multirow{4}{*}{$\begin{array}{l}23,93^{\mathrm{a}} \\
21,88^{\mathrm{b}}\end{array}$} \\
\hline & Habitat Natural & 21,83 & 21,93 & \\
\hline & Média & $23,01^{\mathrm{A}}$ & $22,80^{\mathrm{A}}$ & \\
\hline & CV $(\%)$ & & & \\
\hline \multirow{4}{*}{ Extrato etéreo (\%) } & Zoocriadouro & $0,83^{\mathrm{bA}}$ & $0,49^{\mathrm{bB}}$ & $0,66^{\mathrm{b}}$ \\
\hline & Habitat Natural & $5,43^{\mathrm{aA}}$ & $0,54^{\mathrm{aB}}$ & \multirow[t]{3}{*}{$2,98^{\mathrm{a}}$} \\
\hline & Média & $3,13^{\mathrm{A}}$ & $0,51^{\mathrm{B}}$ & \\
\hline & CV (\%) & & & \\
\hline \multirow{4}{*}{ Cinzas (\%) } & Zoocriadouro & 0,91 & 0,99 & \multirow{4}{*}{$\begin{array}{l}0,95^{\mathrm{b}} \\
1,17^{\mathrm{a}}\end{array}$} \\
\hline & Habitat Natural & 1,09 & 1,25 & \\
\hline & Média & $1,0^{\mathrm{B}}$ & $1,12^{\mathrm{A}}$ & \\
\hline & $\mathrm{CV}(\%)$ & & & \\
\hline \multirow{4}{*}{ Colesterol (mg/100g) } & Zoocriadouro & 48,82 & 53,73 & \multirow{4}{*}{$\begin{array}{l}51,23^{\mathrm{a}} \\
38,83^{\mathrm{b}}\end{array}$} \\
\hline & Habitat Natural & 37,05 & 40,61 & \\
\hline & Média & $42,93^{\mathrm{A}}$ & $47,17^{\mathrm{A}}$ & \\
\hline & $\mathrm{CV}(\%)$ & & & \\
\hline
\end{tabular}

Médias seguidas da mesma letra maiúscula na linha e minúscula na coluna não diferem entre si pelo teste $\mathrm{F}(\mathrm{P}>0,05)$. 
As médias de extrato etéreo nos animais $\mathrm{H}$ (5,43 e $0,54 \%$ na cauda e dorso, respectivamente) demonstram que jacarés-do-pantanal tendem a armazenar gordura nos tecidos musculares da cauda, provavelmente para utilizálas em épocas de menor oferta de alimento. Romanelli (1995) reporta valores de extrato etéreo variando de 2,25 a 5,32\% em carne de jacaré-do-pantanal de 2 grupos com pesos diferentes. Forrest et al. (1979) e Pardi et al. (1993) citam que o extrato etéreo é a fração de maior variação na composição da carne.

Miller et al. (1986) observaram que o aumento de gordura nos músculos é acompanhado pelo decréscimo de umidade. Resultado semelhante foi observado por Romanelli (1995) com dois grupos de jacaré-do-pantanal com pesos diferentes $(75,23 \%$ de umidade; $5,32 \%$ de extrato etéreo, para animais de 16,5 a 20,9 kg; e 78,33\% de umidade; $2,25 \%$ de extrato etéreo, para animais de 2,0 a 4,0 kg), sendo também observado no presente estudo.

Comparando a média de extrato etéreo, obtido em cauda e dorso, verifica-se que: estes apresentam valores mais baixos, do que os resultados reportados para espécies domésticas, próximos aos dados relatados por Romanelli (1995) em jacaré-do-pantanal, e diferem dos valores citado por Moody et al. (1980) em jacaré americano selvagem (1,0 a $1,5 \%)$.

As origens interferem $(\mathrm{P}<0,05)$ no valor de proteínas. A média mais elevada foi observada em jacarés $Z(23,93 \%)$, do que em jacarés H $(21,88 \%)$. Esse comportamento pode ser explicado pela relação observada entre redução da média de extrato etéreo e aumento de proteína nos jacarés $\mathrm{Z}(0,66 \%$ de extrato etéreo e $23,93 \%$ de proteínas), quando comparado com os animais $\mathrm{H}$ (2,98\% de extrato etéreo e $21,88 \%$ de proteínas). A variação no percentual de gordura da carne determina oscilações nas proteínas e demais componentes (BANSKALIEVA et al., 2000).

Romanelli (1995) cita valores de proteínas variando de 18,40 a 18,43\% em carne de jacaré-do-pantanal e Moody et al. (1980) reportam valores de $21,1 \%$ a $22,3 \%$, nos quatro cortes estudados, em jacaré americano selvagem. Em carnes de animais selvagens são descritos médias de proteína de 19,56 a 22,8\% (DAWOOD \& ALKANHAL, 1995; LUZ et al., 2003; MARCHIORI, 2001; ZOMBORSZKY et al., 1996) em javalis, cervídeos, camelos e tartaruga da Amazônia. Em espécies domésticas (bovinos, ovinos, perus e frangos) são reportadas variações médias de 17,54 a 20,4\% (NORKUS et al., 2001; PALEARI et al., 1998; SOUZA, 2001). De forma geral, os dados da literatura mostram que em animais silvestres os valores de proteína são mais elevados do que em animais domésticos.
Foi observada diferença $(\mathrm{P}<0,05)$ para os fatores origens e cortes nos teores de cinzas. $\mathrm{O}$ aumento no percentual de cinzas é observado nas diversas espécies animais, em função do crescimento (FORREST et al., 1979), pois parte do conteúdo mineral da carne é associado a compostos orgânicos. Os sais inorgânicos permitem a manutenção da pressão osmótica celular e participam de diversas funções metabólicas, como a contração muscular (PRÄNDL et al., 1994). Isto pode explicar o valor médio de cinzas $(1,17 \%)$ dos animais $\mathrm{H}$ ser maior do que o valor médio dos animais $\mathrm{Z}(0,95 \%)$. Os animais $\mathrm{H}$ mostram maior movimentação e conseqüentemente maior contração muscular. Para jacaré-do-pantanal, Romanelli (1995) reporta médias de cinzas de 1,02 a 1,08\% e em jacaré americano selvagem Moody et al. (1980) reportam médias de 1,0 a $1,5 \%$.

Houve diferença $(\mathrm{P}<0,05)$ entre as origens para colesterol. Essa diferença pode ser atribuída à alimentação dos jacarés. Os animais $\mathrm{Z}$ recebem dieta rica em $\mathrm{PB}(52,9 \%$ a $68,69 \%$ na $\mathrm{MS}$ ), e lipídeos (4 a $12 \%$ na matéria integral) (ALEIXO, 2000; MACIEL, 2001).

Nesse estudo foi observado que o corte com menor valor de colesterol apresenta maior valor de lipídeos totais (independente da origem). Romanelli (1995) observou que jacarés do pantanal que apresentavam valor elevado de extrato etéreo $(5,32 \%)$, o valor de colesterol também foi maior $(85,48 \mathrm{mg} / 100 \mathrm{~g})$, sendo, diferente dos resultados encontrados no presente trabalho. Bragagnolo \& Rodrigues-Amaya (2002), estudando teores de colesterol e lipídeos totais em cortes de carne suína, constataram que quando a quantidade dos lipídeos do músculo é baixa, a concentração de colesterol é alta. Resultados semelhantes foram descritos por Hood (1987), segundo o qual os lipídeos das membranas funcionais contêm maiores concentrações de colesterol do que os lipídeos do tecido adiposo intramuscular.

De forma geral, os animais silvestres apresentam teores de colesterol inferiores aos teores encontrados em carnes de espécies domésticas. São relatados valores (mg/ $100 \mathrm{~g}$ ) de colesterol de 36,99 em catetos fêmeas e 48,78 em catetos machos (FREIRE et al., 2000); de 63,50 em jacarédo-pantanal (ROMANELLI, 1995); de 33,8 a 57,0 em avestruzes (PALEARI et al., 1998); e de 59,0 em emas (SALES et al., 1999). Em nosso estudo foi observado que o músculo dorso de jacaré-do-pantanal apresenta média $(42,93 \mathrm{mg} / 100 \mathrm{~g})$ de colesterol inferior ao músculo cauda $(47,17 \mathrm{mg} / 100 \mathrm{~g})$.

Ciênc. agrotec., Lavras, v. 30, n. 4, p. 701-706, jul./ago., 2006 


\section{CONCLUSÕES}

Os animais criados em cativeiro apresentam melhores características nutricionais (menor quantidade de gordura e maior valor de proteína) quando comparado com os animais do habitat natural.

O corte dorso de jacaré-do-pantanal apresenta as características mais adequadas de composição centesimal e de colesterol.

\section{AGRADECIMENTOS}

Os autores agradecem o apoio do CNPq; da Capes; da FAPEMAT pelas bolsas de Mestrado, Doutorado e produtividade e da Cooperativa de Criadores de Jacarédo-Pantanal - COOCRIJAPAN de Cáceres - MT.

\section{REFERÊNCIAS BIBLIOGRÁFICAS}

ALEIXO, V. M. Efeitos do uso de farelo de soja e de sistemas de alimentação sobre o desempenho de filhotes de jacarédo-pantanal Caiman yacare (DAUDIN, 1802). 2000. 92 p. Dissertação (Mestrado em Zootecnia) - Universidade Federal de Lavras, Lavras, 2000.

ASSOCIATION OF OFFICIAL ANALYTICAL CHEMISTS. Official methods of Analysis of the Association of Official Analytical Chemists. 15. ed. Arlington, 1990.

BANSKALIEVA, V.; SAHLU, T.; GOETSCH, A. L. Fatty acid composition of goat muscles and fat depots: a review. Small Ruminant Research, Amsterdam, v. 37, n. 3, p. 255268, Aug. 2000.

BOHAC, C. E.; RHEE, K. S.; CROSS, H. R.; ONO, K. Assesment of methodologies for colorimetric cholesterol assay of meats. Journal of Food Science, Chicago, v. 53, n. 6, p. 1642-1645, Nov./Dec. 1988.

BRAGAGNOLO, N.; RODRIGUEZ-AMAYA, D. B. Teores de colesterol em carne suína e bovina e efeito do cozimento. Ciência e Tecnologia de Alimentos, Campinas, v. 15, n. 1, p. 11-17, jan./jun. 1995.

BRAGAGNOLO, N.; RODRIGUEZ-AMAYA, D. B. Teores de colesterol, lipídeos totais e ácidos graxos em cortes de carne suína. Ciência e Tecnologia de Alimentos, Campinas, v. 22, n. 1, p. 1-13, jan./abr. 2002.
CRAWFORD, M. A.; CASPERD, M. N.; SINCLAIR, A. J. The long chain metabolites of linoleic and linolenic acids and liver and brain in herbivores and carnivores. Comparative Biochemistry and Physiology B Biochemistry \& Molecular Biology, Oxford, v. 54, n. 3, p. 395-401, 1976.

DAWOOD, A. A.; ALKANHAL, M. A. Nutrient composition of Najdi-Camel meat. Meat Science, Oxford, v. 39, n. 1, p. 71-78, 1995.

DREW, K. R. Carcass characteristics and optimal slaughter time in deer: biology of deer production. The Royal Society of New Zealand, Wellington, v. 22, p. 543, 1985.

FERREIRA, D. F. Análises estatísticas por meio do Sisvar para o Windows versão 4.0. In: REUNIÃO ANUAL DA REGIÃO BRASILEIRA DA SOCIEDADE INTERNACIONAL DE BIOMETRIA, 45., 2000, São Carlos. Anais... São Carlos: UFSCar, 2000. p. 255-258.

FOLCH, J.; LEES, M.; SLOANE-STANLEY, G. H. A simple method for the isolation and putification of total lipids from animal tissue. Journal of Biological Chemistry, Baltimpore, v. 226, n. 1, p. 497-509, May 1957.

FORREST, J. C.; ABERLE, E. D.; HEDRICK, H. B.; JEDGE, M. D.; MERKEL, R. A. Fundamentos de ciencia de la carne. Zaragoza: Acribia, 1979. 364 p.

FREIRE, K. R.; BESERRA, F. J.; PINHEIRO, M. J. P.; NOGUEIRA, C. M.; CARRARO, F. Efeito do sexo e da castração no perfil de ácidos graxos e teor de colesterol da carne de cateto (Tayassu tajacu). In: CONGRESSO BRASILEIRO DE CIÊNCIA E TECNOLOGIA DE ALIMENTOS, 17., 2000, Fortaleza, CE. Anais... Fortaleza: CBCTA, 2000.

HOOD, R. L. A note of cholesterol content of beef rib steaks. CSIRO Food Research Q, [S.1.], v. 47, p. 44-46, 1987.

JARDIM, N. S. Sexo e diferentes pesos ao abate na qualidade da carne de capivara (Hydrochaeris hydrochaeris L. 1766). 2001. 119 p. Dissertação (Mestrado em Ciência de Alimentos) - Universidade Federal de Lavras, Lavras, 2001.

LAWRIE, R. A. Ciência de la Carne. Zaragoza: Acribia, 1967. $380 \mathrm{p}$. 
LUZ, V. L. F.; STRINGHINI, J. H.; BATAUS, Y. S. L.; FERNADES, E. S.; PAULA, W. A. de; NOVAIS, M. N.; REIS, I. J. dos. Rendimento e composição química de carcaça da tartaruga-da-Amazônia (Podocnemis expansa) em sistema comercial. Revista Brasileira de Zootecnia, Viçosa, v. 32, n. 1, p. 1-9, 2003.

MACIEL, F. R. Coeficiente de digestibilidade aparente de cinco fontes energéticas para o jacaré-do-pantanal (Caiman yacare, Daudin, 1802). 2001. 76 p. Dissertação (Mestrado em Zootecnia) - Universidade Federal de Lavras, Lavras, 2001.

MARCHIORI, A. F. Composição e propriedades físicoquímicas da carne de javali e de suíno comercial. 2001. 71 p. Dissertação (Mestrado em Tecnologia de Alimentos) Universidade de Campinas, Campinas, 2001.

MIGUEL, G. Z. Caracterização da carcaça e da carne de capivaras (Hydrochaeris hydrochaeris L. 1766) em idade adulta. 2002. 107 p. Dissertação (Mestrado em Ciência de Alimentos) - Universidade Federal de Lavras, Lavras, 2002.

MILLER, G. J.; FIELD, R. A.; RILEY, M. L.; WILLIAMS, J. C. Lipids in wild ruminant animals and steers. Journal Food Quality, Wastport, v. 9, p. 331-343, 1986.

MOODY, M.; COREIL, P. D.; RUTLEDGE, J. E. Alligator meat: yields, quality studied. Lousiana Agriculture, Lousiana, v. 24, n. 1, p. 14-15, 1980.

NAUGHTON, J. M.; O’DEA, K.; SINCLAIR, A. J. Animal foods in tradicional aboriginal diets: polyunsaturated and low in fat. Lipids, Champaign, v. 21, n. 11, p. 684-690, Nov. 1986.

NORKUS, E. A.; SOUZA, H. B. A.; SOUZA, P. A.; OBA, A.; KODAWARA, L. M.; LEONEL, F. R.; PELICANO, E. R. L. Avaliação da qualidade física e química da carne de frangos abatidos com diferentes idades. In: CONGRESSO BRASILEIRO DE CIÊNCIA E TECNOLOGIA DE CARNES, 1., 2001, São Pedro, SP. Anais... São Pedro: CTC/ITAL, 2001.

PALEARI, M. A.; CAMISASCA, S.; BERETTA, G.; RENAN, P.; CORISCO, P.; BERTOLO, G.; CRIVELLI, G. Ostrich meat physico chemical characteristics and comparison with turkey and bovine meat. Meat Science, Oxford, v. 48, n. 3/ 4, p. 205-210, Mar./Apr. 1998.

PARDI, M. C.; SANTOS, I. F.; SOUZA, E. R.; PARDI, H. S. Ciência, higiene e tecnologia da carne: tecnologia da sua obtenção e transformação. Goiânia: Universidade de Goiás, 1993. v. 1, 586 p.

PRÄNDAL, O.; FISCHER, A.; SCHMIDHOFER, T.; SINELL, H. J. Tecnología e hygiene de la carne. Zaragoza: Acribia, 1994. $854 \mathrm{p}$.

PRICE, J. F.; SCHWEIGGERT, B. S. Ciência de la carne y de los productos carnicos. Zaragoza: Acribia, 1976. 668 p.

REESE, A. M. The alligator and its allies. Landisville: Arment Biological, 2000. 229 p.

ROMANELLI, P. F. Propriedades tecnológicas da carne do jacaré do pantanal Caiman crocodilus yacare (Daudin, 1802). 1995. 110 f. Tese (Doutorado em Tecnologia de Alimentos) - Universidade de Campinas, Campinas, 1995.

SALDANHA, T. Determinação da composição centesimal nos diferentes cortes da carne de capivara (Hydrochoerus hydrochaeris). 2000. 105 f. Dissertação (Mestrado em Ciência e Tecnologia de Alimentos) - Universidade Federal Rural do Rio de Janeiro, Rio de Janeiro, 2000.

SALES, J.; NAVARRO, J. L.; MARTELLA, M. B.; LIZURUME, M. E.; MANERO, A.; BELLIS, L.; GARCIA, P. T. Cholesterol content and fatty acid composition of rhea meat. Meat Science, Oxford, v. 53, n. 2, p. 73-75, Oct. 1999.

SANTOS, S. A. Dieta e nutrição de crocodilianos. Corumbá: EMBRAPA-CPAP, 1997. 59 p. (Documentos, 20).

SINCLAIR, A. J.; O'DEA, K. Fats in Human diets through history: is the western diet out of step? In: WOOD, J. D.; FISHER, A. V. Reducing fat in meat animals. London: Elsevier, 1990. p. 1-47.

SOUZA, X. R. Efeitos de grupo genético, sexo e peso ao abate na qualidade de carne de cordeiros em crescimento. 2001. 116 p. Dissertação (Mestrado em Ciência dos Alimentos) - Universidade Federal de Lavras, Lavras, 2001.

VILAS-BOAS, E. V. de B. Avaliação nutricional dos alimentos. Lavras: UFLA/FAEPE, 1999. 51 p.

ZOMBORSZKY, Z.; SZENTMIHÁLYI, G.; SARUDI, I.; HORN, P.; SZABÓ, C. S. Nutrient composition of muscles in deer and boar. Journal of Food Science, Chicago, v. 61, n. 3, p. 625-626, May/June 1996. 